\title{
NO PORTUGUESE, PLEASE
}

\begin{abstract}
Alice Leal ${ }^{1}$
No conto "Ein Tisch ist ein Tisch" ("Uma mesa é uma mesa"), do escritor suíço Peter Bichsel, há um homem que, insatisfeito com a monótona constância da sua vida, decidiu calar-se. Um certo dia, perguntou-se por que a cama chamava-se cama, em vez de quadro, por exemplo. A princípio achou graça; depois, resolveu que, daquele momento em diante, cama passaria a chamar-se quadro. Adotou a mesma estratégia de renomeação para todos os objetos à sua volta, e, finalmente, teve a impressão de que alguma coisa mudara em sua vida. Rapidamente aprendeu todos os nomes novos, tomou nota e, gradativamente, foi se esquecendo dos nomes antigos inventara uma língua só para si. Com o passar dos tempos, tornou-se incapaz de se comunicar com as outras pessoas, pois esquecera completamente a sua língua materna. Quando diante das outras pessoas, o receio foi lentamente substituído pela jocosidade ria ao ouvir os outros falarem, já que não mais entendia coisa alguma.

Em sala de aula, um processo análogo parece se dar com os alunos - guardadas as proporções. Nós, professores, somos o impulso inicial que os faz, gradualmente, deixar sua língua materna de lado - no caso dos professores que trabalham com abordagens comunicativas, para os quais a língua materna é uma espécie de perigo iminente, uma ameaça ao aprendizado —, nem que seja por algumas horas por semana, apenas. Tal processo é extremamente doloroso e árduo, tanto para nós, professores, quanto para os alunos. Afinal, convencê-los de que devem utilizar uma língua que desconhecem completamente não é nada fácil. E, certamente, aqueles professores que já vivenciaram o aprendizado de uma língua estrangeira desde os níveis mais básicos podem imaginar quão penoso é começar a usar uma língua estranha, quando se é capaz sequer de formular uma frase completa corretamente. Para aqueles que nunca tiveram tal experiência, basta imaginar como seria se um professor

\footnotetext{
${ }^{1}$ Alice Leal é Bacharel em Estudos da tradução - Letras (inglês - português) pela UFPR e professora de inglês e tradutora na Phil Young's English School; mestranda em estudos da tradução pela UFSC.
} 
de uma língua absolutamente desconhecida por você lhe pedisse, no primeiro dia de aula, para não falar português em hipótese alguma, e para utilizar somente aquela língua na qual você não sabe nem dizer 'eu' com segurança. Não é à toa que muitos alunos julgam seus professores malucos nas primeiras semanas de aula.

Todavia, como num passe de mágica, a loucura inicial parece mesmo ter algum método. Aos poucos os alunos sucumbem, param de resistir à língua estrangeira e abandonam sua língua materna por completo. As perguntas já saem naturalmente na língua estrangeira, assim como os diálogos de sala de aula. Até mesmo as conversas paralelas e os cochichos sorrateiros obedecem à regra sagrada, estabelecida no primeiro dia de aula. Certamente, nos níveis mais básicos, as frases ainda são incompletas, ou contêm alguns erros. Não obstante, a comunicação não é prejudicada, e cada aula é como passar algumas horas num país estrangeiro. De fato, para alguns alunos, aprender uma língua estrangeira desta forma é como mergulhar em outra cultura, viajar para outro país semanalmente.

Ouvir o professor falar português é como ouvir um estranho. Isso sem falar na sempre esquisita experiência de encontrar um aluno num local público, que instintivamente começa a falar na língua estrangeira, atraindo a atenção de todos em volta. A sua decepção ao ouvir o professor falar em português, envergonhado, é indescritível. Muitos expressam espanto, "Professor? O que você faz aqui?". Talvez pensassem que éramos movidos à corda, e que, no fim do dia, éramos dobrados e guardados em grandes armários na escola, para no dia seguinte sermos ativados novamente.

É claro que, freqüentemente, algumas estratégias sutis para convencer os alunos a se curvarem diante da regra sagrada se fazem necessárias. Alguns professores utilizam um objeto qualquer (um giz, caneta ou pequeno brinquedo) que deve ser dado àquele que falar português. Na medida em que outros alunos falam português, o objeto é passado para cada um deles, de modo que alguém, ao término da aula, acabe ficando ele. Este aluno é, então, condenado a fazer alguma coisa especial na aula seguinte cantar uma canção, contar uma piada, recitar um poema, contar uma história, etc. Outros professores lançam mão de estratégias mercantilistas, como recolher dez 
centavos do aluno que falar português, para depois, no final do semestre, oferecer alguma coisa com o dinheiro — doces, por exemplo.

A tradução é, nesses casos, uma espécie de recaída, que pode ser sofrida tanto pelos alunos quanto pelo professor. No primeiro caso, uma severa punição se faz necessária. Afinal, não há tabus em sala de aula — fala-se sobre tudo —, a não ser falar português. Já no segundo, é preciso entender que nem sempre é fácil mimicar uma abobrinha, imitar um ornitorrinco ou explicar o que é uma angurucemanvula ${ }^{2}$. De todo modo, a cada vez que o idioma profano é utilizado, seja pelo professor ou pelos alunos, um espírito de culpa paira no ar. Tamanho é o comprometimento de alguns alunos, que eles reclamam daqueles professores que recorrem ao português com mais freqüência - alegam sentir-se tentados a retornar à língua materna por culpa do professor. Com efeito, sob este aspecto, aprender uma língua estrangeira requer uma espécie de tratamento de reabilitação, como aqueles vivenciados por pacientes com algum vício - neste caso, um hábito, a saber, a língua materna. De modo a auxiliar os alunos em tal processo, alguns professores valem-se de 'super-traduções', como falar nomes brasileiros com o sotaque da língua estrangeira, ou até mesmo traduzir certos nomes próprios - como nomes de cidades e bairros, por exemplo —, a fim de afastálos da constante tentação da língua materna.

Voltando ao conto suíço, este processo gradual de substituição da língua materna não faz os alunos esquecerem-se dela, obviamente. Entretanto, tamanho é o deslocamento produzido em sala de aula, que os alunos parecem se esquecer completamente, pelo menos durante as aulas, de que falam outra língua, que, aliás, vêm falando desde muito pequenos. Esperam da língua estrangeira regularidades absolutas que não existem em sua língua materna. Têm dificuldades em aceitar certas arbitrariedades, e revoltam-se quando o professor diz que não há regra que dê conta de determinada questão. O fato de que o português, por exemplo, também tem preposições cuja aplicação parece não obedecer a regras parece escapar à sua memória.

\footnotetext{
2 "Inquice" correspondente à Iansã do panteão nagô" (HOUAISS, 2004).
} 
Um colega professor de inglês uma vez relatou uma experiência de sala de aula, que de relato mais parece uma anedota, e que parece ilustrar o ponto muito bem. Um aluno, estarrecido com o fato de que o adjetivo inglês cool, que estava acostumado a utilizar com o sentido de 'frio', como gíria poderia significar 'legal', 'bacana', ‘ótimo’. Ora, não parecia haver relação direta entre os dois sentidos, o que justifica a perplexidade do aluno. O professor, por sua vez, poderia ter the explicado que cool também remete à idéia de 'frescor', 'calmaria' e 'conforto', expressões positivas, portanto. Contudo, ele preferiu apenas fazer uma simples pergunta ao aluno, "O que significa 'massa', em português?'. Diante da pergunta, o aluno calou-se, conformado e um pouco contrariado.

Seria papel do professor fazer essas associações com a língua materna em sala de aula? Ou será que se o professor, desde o princípio, não afastar a língua materna por completo, os alunos serão capazes de estabelecer tais relações por si próprios? Será que, deste modo, a influência constante do português não prejudicaria o aprendizado? Algumas abordagens mais recentes ao ensino de línguas estrangeiras apontam, entre outras coisas, para o fato de que não há quatro competências - escrita, leitura, compreensão e conversação. Afirmam, também, que dentre as habilidades do falante está a tradução, ou a esta capacidade de compreender línguas enquanto sistemas, e de estabelecer relações entre estes sistemas - o chamado plurilingüismo, em detrimento do antigo multilingüismo ${ }^{3}$.

Pessoalmente, prefiro trabalhar com essas associações entre línguas, em sala de aula, com alunos de nível avançado. Os alunos de nível básico e intermediário parecem de fato necessitar de um tratamento de choque contra o português, para que aprendam a pensar na língua estrangeira, e para que a compreendam como um sistema independente do português. Quando chegam aos níveis avançados, os alunos estão completamente imersos na língua estrangeira, de modo que a língua materna não mais constitui uma ameaça. Fazê-los refletir acerca do português na aula de língua

\footnotetext{
3 Para informações detalhadas, ver GIRARD; TRIM (1998), NORTH (1994 e 2000), BERTHOUD (1996).
} 
estrangeira não é mais tão arriscado para o professor, e nem conflitante para o aluno, e mostra-se uma estratégia muito frutífera de aprendizado.

Com efeito, esta competência associativa parece caracterizar-se como uma competência fundamental do falante, sobretudo hoje em dia que falamos muitas línguas ao mesmo tempo. Resta-nos saber se ela pode ser trabalhada desde os níveis mais básicos, de que forma e quais são os resultados.

\section{REFERÊNCIAS BIBLIOGRÁFICAS}

BERTHOUD, A.-C. (Ed.). Acquisition des compétences discursives dans un contexte plurilingue. Bulletin Suisse de linguistique appliquée, VALS/ASLA 64, 1996.

BICHSEL, P. O homem que não queria saber mais nada. São Paulo: Ática, 2002.

GIRARD, D.; TRIM, J. L. M. (Ed.). Project $\mathbf{n}^{\circ} .12$ 'Learning and teaching modern languages for communication': Final Report of the Project Group (activities 198287). Strasbourg, Council of Europe, 1998.

NORTH, B. The Development of a Common Reference Scale of Language Proficiency. New York: Peter Lang, 2000.

Perspectives on language proficiency and aspects of competence: a reference paper discussing issues in defining categories and levels. Strasbourg, Council of Europe. North B. and Schneider, G. (1998): 'Scaling Descriptors for Language Proficiency Scales'. Language Testing 15/2: 217-262. 